\title{
The Mass Spectra of Some Dialkylthiolsulfonates
}

\author{
W. G. Filby, K. Günther, and R.-D. Penzhorn \\ Institut für Radiochemie, Kernforschungszentrum Karlsruhe \\ (Z. Naturforsch. 31 b, 463-465 [1976]; received December 12, 1975)
}

Mass Spectra, Dialkylthiosulfonates

\begin{abstract}
The mass spectra of six symmetrically $\left(R^{\prime}=R\right)$ and three unsymmetrically $\left(R^{\prime} \neq R\right)$ substituted dialkylthiolsulfonates have been determined. With the exception of the diethyl derivative the base peak is derived from direct fission of the sulfinyl $\mathrm{S}-\mathrm{R}$ bond. Fission of the S-S bond with rearrangement and rearrangement of the alkyl residue are two further processes of importance enabling characterisation of the species.
\end{abstract}

The mass spectroscopy of organic sulfoxy compounds is not an area replete with information ${ }^{1,2}$. For, while the spectra of sulfinates, sulfonates, sulfones and sulfoxides have been amply catalogued knowledge in general is sparse on other members of the group $\mathrm{R} \mathrm{S}_{x} \mathrm{OyR}$. Indeed only recently have systematic chemical studies begun on the thiosulfinates $(x=2, y=1)^{3}$.

During the course of a study of reactions of photochemically excited sulfur dioxide with lower alkanes ${ }^{4}$ we synthesised a series of symmetrically and unsymmetrically substituted thiolsulfonates $(x=2, y=2)$ for use as reference compounds. Here we report the mass spectra of these taken directly via a combined m.s.-g.l.c. system. So far as the authors are aware this is the only report dealing specifically with dialkylthiosulfonates although recently $\mathrm{OAE}_{\mathrm{AE}}$ et al. have reported briefly on the mass spectra of four diaryl derivatives.

\section{Experimental}

Symmetrically substituted thiolsulfonates $(R=R$; $\mathrm{Et}, \mathrm{Pr}, \mathrm{iPr}, \mathrm{secBu}, \mathrm{iBu}, \mathrm{tBu})$ were prepared by thermolysis of the corresponding sulfinic $\operatorname{acid}^{5}$, followed by alkali carbonate extraction to remove sulfonic acid. Distillation ( $\sim 5$ torr) yielded products of generally better than $95 \%$ purity. Unsymmetrical thiolsulfonates $\left(\mathbf{R}^{\prime} \neq \mathbf{R}\right.$ : iPr, $\mathrm{Bu}$; $\mathrm{iPr}$, secBu; iPr, iBu) were prepared via the metathesis of alkylsulfonyl bromide and silver mercaptide according to the method described in ref. ${ }^{6}$.

A computer m.s./g.l.c. system (Varian CH5Aerograph 1740) was used to demonstrate the

Requests for reprints should be sent to Dr. W. G. FILBY, Institut für Radiochemie, Gesellschaft für Kernforschung mbH, Weberstraße 5, D-7500 Karlsruhe. purity of the sample and for measurement of the mass spectra. The electron energy was $70 \mathrm{eV}$. Data acquisition and processing was performed on a Telefunken TR-86 computer.

\section{Results and Discussion}

a) The symmetrical members ( $\mathrm{R} \mathrm{SO} \mathrm{SR}_{2} \mathrm{SR}=\mathrm{R}$ )

The mass spectra of the dialkylthiosulfonates presented here (Table I) are relatively simple and show, in comparison to their oxygen analogues (dialkylsulfonates) ${ }^{7}$, much less tendency to rearrangement peaks, an observation clearly associated with the extreme ease of fission of the sulfinyl S-R bond (see below).

In common with the isoelectronic alkanesulfonate spectra the molecular ions are of low abundance, only exceeding $10 \%$ in the case of the diethyl derivative. This is in contrast to the observations of $\mathrm{OAE}_{\mathrm{AE}}$ et al. ${ }^{8}$ who observed molecular ions of up to $40 \%$ relative abundance in the spectra of diarylthiolsulfonates. $(\mathrm{M}+1)$ and $(\mathrm{M}+2)$ peaks are however, unlike in the sulfonate spectra, completely absent here. With the exception of the diethyl derivative $(2 \%)$ all substances investigated show, as base peak, the alkane fragment $(\mathbf{R} \cdot)^{+\cdot}$, presumably arising from cleavage from the sulfinyl sulfur. The parent thiol (RSH) ${ }^{+} \cdot$ ion appears as base peak in the diethyl case. This latter ion could be favoured by the ease of formation via rearrangement of the six membered transition state (1).

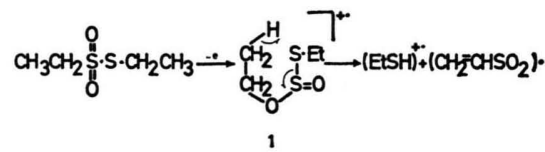


Table I. The mass spectra of some dialkylthiolsulphonates $\mathrm{R}^{\prime} \mathrm{SO}_{2} \mathrm{SR} *$. Ionising voltage $70 \mathrm{eV}$.

\begin{tabular}{|c|c|c|c|c|c|c|c|c|c|}
\hline Ion $R, R$ & $\begin{array}{l}\text { Et,Et } \\
(154)\end{array}$ & $\underset{(182)}{n \operatorname{nPr}, n \operatorname{Pr} .}$ & $\begin{array}{l}\text { iPr,iPr. } \\
(182)\end{array}$ & $\begin{array}{l}\text { secBu,secBu } \\
(210)\end{array}$ & $\begin{array}{l}\mathrm{iBu}, \mathrm{iBu} \\
(210)\end{array}$ & $\begin{array}{l}\text { tBu,tBu } \\
(210)\end{array}$ & $\begin{array}{l}\mathrm{iPr}, \mathrm{nBu} \\
(196)\end{array}$ & $\begin{array}{l}\mathrm{iPr}, \mathrm{secBu} \\
(196)\end{array}$ & $\begin{array}{l}\mathrm{iPr}, \mathrm{iBu} \\
(196)\end{array}$ \\
\hline $\mathbf{M}+1$ & & & & & 1 & & - & & \\
\hline M & 39 & 2 & 7 & 1 & & 3 & - & & \\
\hline $\mathrm{R}$ & 2 & 100 & 100 & 100 & 96 & 100 & 100 & 100 & 100 \\
\hline R-1 & 6 & 64 & 11 & 35 & 96 & 9 & 24 & 23 & 17 \\
\hline $\mathrm{RSH}$ & 100 & 90 & 34 & 14 & 53 & 6 & 10 & 9 & 6 \\
\hline $\mathrm{RS}$ & 89 & 19 & 29 & 12 & 21 & 5 & 19 & 22 & 12 \\
\hline$(\mathrm{R}-1) \mathrm{CH}=\mathrm{S}$ & 37 & 15 & 14 & 8 & 32 & - & - & 19 & 1 \\
\hline$(\mathrm{R}-1) \mathrm{C}=\mathrm{S}$ & 17 & 6 & 3 & - & 4 & - & - & 1 & 1 \\
\hline $\mathrm{R}-\mathrm{S}-\mathrm{R}$ & 5 & 15 & 2 & 5 & 11 & - & - & - & - \\
\hline $\mathrm{R}-\mathrm{SO}_{2} \mathrm{H}(\mathrm{RSSH})$ & 78 & 2 & 1 & - & - & 5 & - & - & - \\
\hline $\mathrm{R}-\mathrm{SO}_{2}(\mathrm{RSS})$ & 7 & 1 & - & - & - & - & & - & - \\
\hline $\mathrm{R}-\mathrm{SO}$ & 31 & 2 & - & - & - & - & - & - & - \\
\hline $\mathrm{R}^{\prime}$ & - & - & - & & & - & 7 & 4 & 13 \\
\hline$R^{\prime}-1$ & - & - & & & & - & 5 & 6 & 5 \\
\hline $\mathrm{C}_{3} \mathrm{H}_{5}$ & - & - & 43 & & 100 & & 79 & 96 & 76 \\
\hline$R^{\prime} S$ & & & & & & & - & 1 & 1 \\
\hline$\left(\mathrm{R}^{\prime}-1\right) \mathrm{CH}=\mathrm{S}$ & & & & & & & - & 1 & 1 \\
\hline$\left(R^{\prime}-1\right) C=S$ & & & & & & & - & 3 & 4 \\
\hline
\end{tabular}

* Molecular weight given in brackets.

Dominant peaks also arise, ostensibly from the following processes: cleavage of the $\mathrm{S}-\mathrm{S}$ bond with rearrangement $\left(\mathrm{RSH}^{+}, \mathrm{R} \mathrm{SO}{ }_{2} \mathrm{H}^{+\cdot}, \mathrm{CH}_{3} \mathrm{CH}=\mathrm{S}^{+\cdot}\right.$ ) and without rearrangement $\left(\mathrm{RS}^{+} \cdot, \mathrm{RSO}^{+\cdot}, \mathrm{R} \mathrm{SO}_{2}{ }^{+\cdot}\right)$, loss of molecular $\mathrm{SO}_{2}$ and of olefine ( $\mathrm{R}-1$ large and $\mathbf{R}^{\prime}-1$ small). Interestingly the diethyl derivative shows a large peak apparently arising from molecular rearrangement (oxygen crossover 2) and cleavage of the sulfinyl S-S bond.

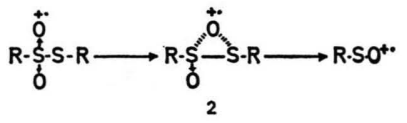

OAE et al. ${ }^{8}$ noted an analogous species (2) in their study of diaryl derivatives, but his observation has recently been disputed by BLOCK ${ }^{3}$. In general it may be mentioned that most of the peaks discussed above are all present in the spectra of the diaryl derivatives albeit with varying degrees of importance.

b) The unsymmetrical members $\left(\mathrm{R}^{\prime} \mathrm{SO}_{2} \mathrm{SR}, \mathrm{R}^{\prime} \neq \mathrm{R}\right)$

The main point of note in this case is the dominance of the alkyl anion $\mathrm{R}^{+\cdot}$ in comparison to the relatively minor nature of the $R^{\prime+\cdot}$ anion ( $\leq 13 \%$ ). It is this observation that leads us to postulate a similar mechanism in the symmetrical derivatives. Qualitatively the two groups of spectra ( $a$ and $b$ ) are similar, striking is however the high intensity of the allyl ion $\left(\mathrm{C}_{3} \mathrm{H}_{5}\right)$ peak in isopropyl derivatives resulting from a presumably, particularly favoured fragmentation (see below).

A comparison between the spectra published here and those of diaryl derivatives ${ }^{8}$ demonstrates some interesting similarities and differences. i) the molecular ion is, in general, much less intense in alkyl derivatives than in their aryl analogue (unsubstituted diphenylthiolsulfonate), ii) the peak derived from direct fission of the S-S bond, strong in the aryl series is either weak or completely absent in the dialkyl derivatives. The effect is probably associated with the fact that in the diaryl series the ions can delocalize their charge by formation of two resonance stabilised ions - a process impossible in the alkyl series, iii) deoxygenation (if at all occuring) and S-S fission appears to be of minor importance in the dialkyl series, iv) in neither case are ions of the type $\mathrm{R} \mathrm{SO}_{2}{ }^{+\cdot}$ observed, meaning that the charge must be entirely localised on $\mathbf{R}^{+}$or that the fragmentation of $\mathrm{R} \mathrm{SO}_{2} \mathrm{~S}^{+}$is extremely rapid.

We can summarise the processes leading to fragmentation of dialkylthiosulfonates as follows. The first member investigated, diethylthiolsulfonate, fragments somewhat differently to the remaining compounds preferring S-S bond fission with and 
without hydrogen transfer. Formation of the thiyl and sulfinyl anions probably proceeds prior rearrangement via the six membered transition states shown below (of the mass spectra of alkane sulfonates).
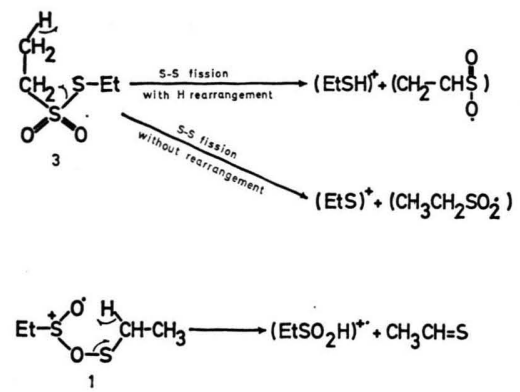

We have already presented arguments elsewhere ${ }^{9}$ supporting this type of fragmentation in the spectra of methyl alkanesulfinates. Two further peaks probably arise via reactions of the type

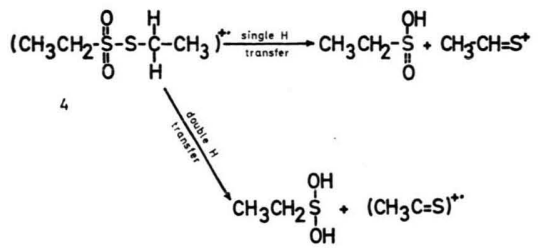

BLOCK and O'CoNNOR ${ }^{3}$ recently postulated an analogous fragmentation to account for peaks in the spectra of $\mathrm{MeSO}_{2} \mathrm{SMe}$ and $\mathrm{MeSO}_{2} \mathrm{SCD}_{3}$. The remaining features of the diethylthiolsulfonate spectrum are identical to that of the higher members presented in Table I. These are characterised by the fact that the base peak is derived almost exclusively via fission of the sulfinyl $\mathrm{S}-\mathrm{R}$ bond (i). This is in

1 H. Budzikiewicz, C. DJerassi, and D. H. WILLIAMS, Interpretation of Mass Spectra of Organic Compounds, Holden-Day, San Francisco 1964.

2 J. H. Beynon, R. A. Saunders, and A. E. WILLIAMs, The Mass Spectra of Organic Molecules, Elsevier Publishing Company, Amsterdam 1968.

3 E. Block and J. O'Connor, J. Amer. Chem. Soc. 96, 3921 [1974].

4 R.-D. Penzhorn, W. G. Filby, K. Günther, and L. Stieglitz, Intl. J. Chem. Kinetics Symb. 1, 611 [1975].

5 C. M. Bere and S. Smiles, J. Chem. Soc. 125, 2359 [1924]. contrast to the sulphonate esters where the base peaks are derived by fission of the $\mathrm{R}$-sulfonyl bond (ii).

$$
\begin{aligned}
& \left(\mathbf{R}^{\prime} \mathrm{SO}_{2} \mathrm{SR}\right)^{+\cdot} \rightarrow\left(\mathbf{R}^{\prime} \mathrm{SO}_{2} \mathrm{~S}\right)^{+}+(\mathrm{R})^{\cdot} \\
& \left(\mathrm{R}^{\prime} \mathrm{SO}_{2} \mathrm{OR}\right)^{+\cdot} \rightarrow\left(\mathbf{R}^{\prime}\right)^{+}+\left(\mathrm{ROSO}_{2}\right)^{\circ} .
\end{aligned}
$$

Peaks due to the latter are, of course, only visible in the unsymmetrical case albeit to a maximum intensity of $\leq 15 \%$ (Table I). Simple S-S fission (cf. S-O fission in sulfonates) apparently takes place in competition with rearrangement and is strongly dependant on structure (Table I).

Another peak of interest is the $\mathrm{R}_{2} \mathrm{~S}^{+}$ion. It is present in low intensity in the symmetrical thiolsulfonates and appears to arise via a three centre rearrangement involving loss of molecular $\mathrm{SO}_{2}$.

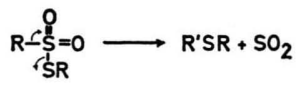

A similar mechanism was envisaged by MATSEN 10 to account for the unimolecular expulsion of sulfur, sulfur monoxide and sulfur dioxide from sulfides, sulfoxides and sulfones respectively.

The formation of the peak ascribed to $\mathrm{C}_{3} \mathrm{H}_{5}+$. appears to be favoured in the case of isopropyl derivatives. It probably arises via a $\beta, \gamma$ hydrogen transfer in a 3,2,1 bicyclic transition state

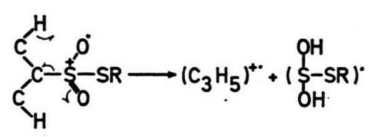

It's absence from other members of the group probably results from effective competition by other more favoured fragmentation processes mentioned above.

6 For a review of methods available for the synthesis of these compounds see Houben-Weyl, ,,Methoden der Organischen Chemie", Edn. 4, George Thieme Verlag, Stuttgart 1955.

7 W. E. Truce, R. W. CAMpbell, and G. D. Madding, J. Org. Chem. 32, 308 [1967].

8 S. Kozuka, H. Takahishi, and S. OAe, Bull. Chem. Soc. Jap. 43, 129 [1970].

9 W. G. Filby, R.-D. Penzhorn, and L. Stieglitz, Organic Mass Spectrometry 8, 409 [1974].

10 J. Madsen, C. Nolde, S. Lawesson, G. Scholl, J. H. Bowie, and D. H. Williams, Tetrahedron Letters 1965, 4377. 